search, which were presented to the whole group of participants in a succeeding plenary session. At least one of the small groups decided to edit a joint review paper based on the topics discussed during that afternoon.

Richard Dikau chaired the final plenary discussion on Sunday morning. His introduction dealt with the development of LUCIFS objectives and approaches over the past 6 years and included a critical review of past deficiencies. The discussions addressed future LUCIFS research strategies against the backdrop of the workshop contributions and current approaches to Earth System Science and will result in a revised LUCIFS research plan. Workshop contributions and results will be published in a special issue of Geomorphology (Elsevier). People interested in LUCIFS activities are invited to visit the PAGES Focus 5 homepage (www. pages-igbp.org/science/research/focus5.html) for further information.

\section{ACKNOWLEDGMENTS}

The Deutsche Forschungsgemeinschaft (DFG) gave considerable support by covering all workshop costs including staff appropriations for the large number of student helpers. PAGES co-sponsored the workshop by funding the travel costs of a number of participants from Eastern Europe and South America.

\section{Peter Houben}

Wolfgang Goethe University, Frankfurt, Germany; houben@em.uni-frankfurt.de

\title{
Linkage between marine and terrestrial processes during past rapid climatic changes
}

Barcelona, Spain; 13-15 March 2006

This workshop was organized by a new working group of the INQUA Commission on Coastal and Marine Processes. The group was inspired by our sadly missed colleague, Nick Shackleton, with the aim of analyzing paleoclimatic records from an integrated marine and terrestrial perspective. The objective of the workshop was to identify key scientific questions that could be addressed through future drilling/coring programs. New data sets from various regions (Fig. 1) were reviewed, and stimulated discussions on atmospheric and oceanic processes active in propagating and modulating past rapid climatic variability:

Zone 1: Sediment cores from the delta fan systems of the Congo Ogooué, Nyong and Sanaga rivers record changes in river discharge associated with latitudinal migration of the Intertropical Convergence Zone (ITCZ) over Africa during the last deglaciation and Holocene periods.

Zone 2: The evolution of the East African ITCZ was discussed on the basis of sediment cores from the Nile delta fan, which records changes in the hydrological regime of the Nile catchment regions.

Zone 3: The humidity evolution of North Africa and the interplay between low- and high-latitude processes during rapid climatic changes were discussed by

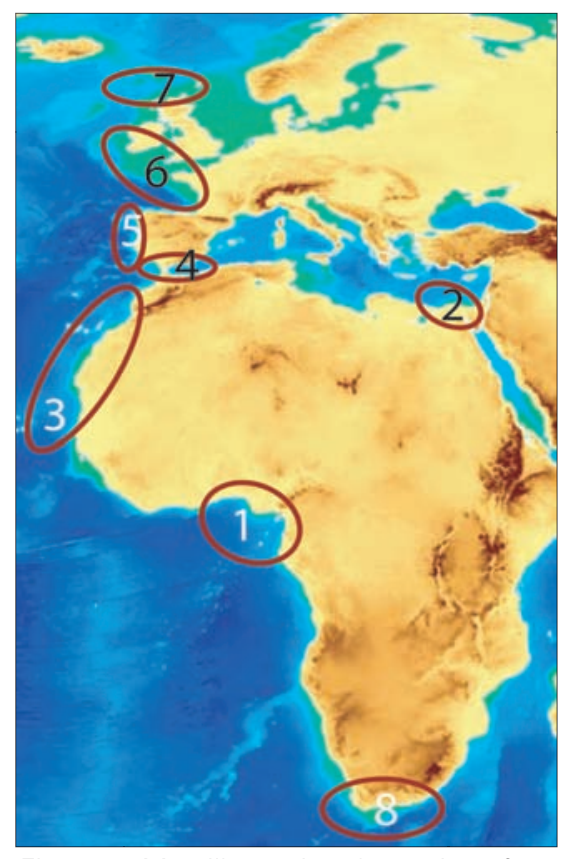

Figure 1: Map illustrating the regions from which data were presented and discussed during the workshop: (1) F. Marret and S.-Y. Kim; (2) S. Weldeab; (3) L. Dupont and O. Romero; (4) I. Cacho, F. Martinez, F. Lobo, L. M. Fernández-Salas, E. Llave and J. Hernandez-Molina; (5) F. Abrantes, T. Rodriques, L. Pena, C. Tzedakis and M. F. Sanchez-Goñi; (6) J. Scourse; (7) W. Austin and I. Hall; (8) I. Hall. Map Source: IHO-UNESCO, General Bathymetric Chart of the Oceans, Digital Edition, 2003, www.ngdc.noaa.gov/mgg/gebco (thanks to B. de Mol for data map processing).

means of new high-resolution records from around Cape Blanc and off Morocco.

Zone 4: Multi-proxy analyses of Alboran Sea sediments provide records of both marine and terrestrial processes at Dansgaard-Oeschger frequency. Geophysical data from shallow areas in the Gulf of Cadiz and
Alboran Sea were discussed for their potential in obtaining ultra-high resolution records. New data from the Gulf of Cadiz provided the basis for an IODP drilling proposal under evaluation.

Zone 5: The Western Iberian Margin is a unique area for marine-terrestrial linkage at centennial-millennial scale. New Holocene records off the Tagus River resolve decadal changes linked to the North Atlantic Oscillation (NAO). Holocene sediments from the Galician Rias record changes in the Meridional Overturning Circulation (MOC). Marine pollen records suggest different timing in the evolution of vegetation and sea level, providing an intriguing insight into the feedback mechanisms during glacial interceptions.

Zone 6: Sediments from the southwestern British Margin record the millennial-scale evolution of the British ice sheets (BIS). The role of the British Shelf in emitting or trapping atmospheric $\mathrm{CO}_{2}$ was discussed on the basis of model and proxy data of sea level, tidal dynamics and primary production.

Zone 7: The North British Margins provide sequences with extraordinary potential to study BIS sensitivity, and the interplay between surface oceanography and MOC. New records 


\section{Workshop Reports}

from the Scottish Fjords show the potential for monitoring past decadal changes linked to the NAO.

Zone 8: The Atlantic-Indian Ocean connection in relation to South African climate was discussed in the context of new sediment records from the Agulhas Current and a submitted IODP drilling proposal.

Future group activities will involve new workshops focusing on spe- cific regions such as the N. African and W. Mediterranean regions and the British Margin, to work on future drilling proposals. We also plan a thematic workshop on the geographical distribution of Heinrich event signatures across the $\mathrm{N}$. Atlantic region by September 2007. An associated workshop on "Fjord Environments: Past, Present and Future" (post Challenger 2006 meeting; www.sams.ac.uk/challenger/) will be held in Oban, UK from 15-16 September 2006.

\section{ACKNOWLEDGMenTS}

This workshop was co-sponsored by INQUA, PAGES, the Spanish Ministry of Education and Science (Grant: CGL200523763-E-CLI) and the Faculty of Geology, University of Barcelona.

\section{Isabel Cacho}

University of Barcelona, Spain; icacho@ub.edu

\section{Monitoring Indonesian throughflow variability: Challenges and perspectives}

Kiel, GeRmany; 19-22 July, 2006

The transport and thermohaline stratification of the Indonesian Throughflow (ITF, Fig. 1) influence the heat and freshwater budgets of both the Pacific and Indian Oceans, and alter patterns of heat and water vapor exchange with the atmosphere on a global scale. The ITF, which is tightly linked to regional climate systems, such as the EI Niño Southern Oscillation (ENSO) and the Australasian monsoon, also plays a central role in the global "conveyor" circulation thereby exerting a critical control on Earth's climate. It is likely that the ITF was substantially modulated by changes in the geometry of the Indonesian pathways due to sea level changes during the Pleistocene and tectonic reorganizations of the archipelago during the Cenozoic. Because of its close link with regional climate systems, it may have also experienced more subtle changes during the Holocene. The processes driving ITF variability and its magnitude are, however, not very well constrained nor is the effect of ITF variability on tropical and extra-tropical climate fully understood.

To address these issues a thematic workshop was held from 19-22 July 2006 at the Institute of Geosciences, Kiel University, Germany, attended by 22 scientists from the U.S., Switzerland, France, Germany, China, India, Indonesia, Timor Leste and Australia. The goal of the meeting was to present an

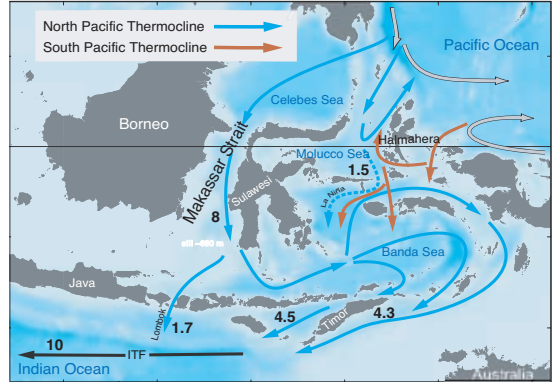

Figure 1: Main pathways of present-day Indonesian Throughflow at thermocline depth and estimates of total volume transport (in Sverdrups). Modified from Gordon (2005)

overview of the latest research initiatives on oceanography and paleoceanography in the ITF region, and to outline urgent research goals for the next few years.

Proxy studies that target the reconstruction of inter-ocean gradients and the transfer of heat, salt and nutrients are crucial. These reconstructions can be accomplished by providing reliable estimates of (1) thermocline structure and temperature in the ITF region, and; (2) ITF circulation changes (intensity, vertical structure of flow and temperature weighted flow). Ultimately, time slice reconstructions should be integrated with modeling studies to evaluate the influence of changing boundary conditions on the ITF (i.e., insolation, volcanic episodes, geometry of passages, sea level), and the linkages between ITF variability and fluctuations in regional and global climate. Time slices of specific interest are:

- Last 50 years
- Little Ice Age (1500-1900) including Tambora eruption (1815) as a marker event

- Medieval Warm Period (1000 $A D \pm 200)$

- Early Holocene (9 ka)

- Last Glacial Maximum (19-23 ka)

- Specific Marine Isotope Stage (MIS) 3 events

- MIS 5e (122 ka)

- MIS 11 (400 ka)

Longer time series will provide insight into (1) the phasing between ITF variations and other factors: warm pool changes, monsoons, atmospheric $\mathrm{CO}_{2}$ and sea level, and; (2) the ITF response to the "mean state of the tropical Pacific" ("ENSO" thermocline tilt, SST distribution). New IMAGES coring initiatives will focus on regions that still have poor core coverage: Makassar Strait, the southern Celebes Sea, east and west of Halmahera, Molucca Sea, Ninetyeast Ridge and West of Sumatra. Since only a few piston cores in this high accumulation rate region will reach back to MIS 12, the drilling of new IODP Sites in the Timor Sea and Makassar Strait will be crucial for evaluating the impact of tectonic and orbital forcing on regional and global climate.

\section{Wolfgang KuHNT}

Christian-Albrechts-Universität, Kiel, Germany:

wk@gpi.uni-kiel.de 